\title{
Energy partitioning and the regulation of body weight - Reply by Millward \& Wijesinghe
}

The regulation of body composition and energy balance is a remarkable phenomenon given that the ability to maintain weight within a few pounds each year with annual intakes of about $4000 \mathrm{MJ}$ of food energy implies that intake is matched by similar losses of energy to within $1 \%$. Interest in the phenomenon has in past times focussed on several aspects of the problem. On the one hand, various control theories have been proposed (set point, cognitive control, dynamic equilibrium (Garrow, 1978)) which have largely attempted to identify what is being controlled and formulate appropriate descriptive or dynamic models. On the other hand, mechanistic explanations have been proposed including the regulation of energy expenditure (e.g. dietary induced thermogenesis and brown fat), and the regulation of energy intake through appetite regulation (with renewed interest in lipostatic mechanisms following the discovery of leptin). Model validation is difficult since data describing actual day-to-day behaviour of free-living individuals is difficult to collect although not impossible, as indicated by the work of de Castro on interrelationships between meal size, frequency and composition, and bodyweight maintenance recently presented to the Society (de Castro, 1997). Most workers in the field draw on either animal data or the few reported studies of marked weight loss and refeeding in humans such as catch-up growth of malnourished infants (Ashworth, 1969; Ashworth \& Millward, 1986) or the classic Minnesota Experiment of Keys and co-workers (Keys et al. 1950).

On the basis of a detailed reanalysis of the Minnesota semi-starvation and refeeding experiment in which body composition and food intake were measured, Dulloo recently described to the Nutrition Society a conceptual model of autoregulation of body composition during weight recovery (Dulloo, 1997) which attempts to combine four separate control systems acting to regulate body weight and composition. These are a non-specific thermogenesis system reacting to food intake, and three additional systems dependent on 'memories of body composition' before weight loss: i.e. a specific thermogenesis dependent on the extent of fat repletion; a hunger-mediated appetite control linked to both repletion of body fat and body lean tissue; and an energy-partitioning system regulating the composition of any body energy change in terms of the relative proportion of protein and fat energy deposited. This is described in terms of a 'P-ratio', with $\mathrm{P}=$ protein energy as a proportion of total energy. In the Dulloo model, $P$ is determined by the characteristic pre-starvation body composition of the individual. The nature of the P-ratio is the subject of the recent report on the relationship between tissue mobilization and storage in the rat (Henry et al. 1997) and of the response to that paper by Dulloo (1998).

The origin of the P-ratio as an important determinant of both weight maintenance and body composition derives from Payne \& Dugdale (1977) who described a dynamic equilibrium model of body-weight regulation which could calculate on a continuing daily basis the response of body weight to changes in energy intake and expenditure. The importance of this model is that it took into account the composition of energy gained or lost and consequent change in body composition, and computed consequent changes in metabolic rate. Increased body size in response to excess energy intake ultimately limits weight gain through associated increased energy expenditure, mainly of the increased lean body mass, and vice versa for body-weight loss. One unique aspect of this model was that its computer program included a variable degree of random variations in energy intake and expenditure around specified mean values so that frequent gains and losses would occur, as in real life. A fixed P-ratio for the composition of energy mobilized or deposited for an individual is central to the model and is necessary for equlibrium of body weight to be achieved at any level of energy intake. Without it, continued drift occurs. As would be expected, programming with a low $P$ value $(P=<0.05)$ results in equlibrium being reached with an obese body composition whilst programming with high $P$ values $(P=>0.2)$ results in a typically lean body composition. The feedback by which changes in energy intake mediate eventual matching gains in energy expenditure involves not only a variable metabolic rate with body size but also a variable metabolic efficiency according to the P-ratio. Since the model described protein deposition as less efficient (more heat production) than fat deposition, losses and gains of predominantly fat (low Pratios) is more efficient (less metabolic heat production) than losses and gains of protein as lean tissue (higher Pratios). The magnitude of this aspect of variation in heat output will be proportional to the amplitude of daily fluctuations in energy loss and repletion (the CV), and input of a low P-ratio will result in the output of less metabolic heat production and more energy gain than input of a high P-ratio. In effect the model generates the same negative influence of increasing body fat on thermogenesis as described by Dulloo (1997).

However, whilst the Payne-Dugdale model is elegant in its metabolic simplicity and the only one to consider seriously body composition and metabolic feedback, it does depend on the central assumptions of both an interindividual variability of the P-ratio (i.e. a ratio which is fixed for an individual at least throughout the major developmental periods of life) and on the intra-individual constancy of the P-ratio (i.e. $P$ is the same for tissue mobilization during weight loss and storage during growth). Only with these conditions can the P-ratio act as the main regulator of body fatness.

Henry et al. (1997) recently reported rat studies of the relationship between tissue mobilization and storage which they conclude provide support for these hypotheses showing that in adult rats the mean values of P-fasting and P-refeeding are the same and individually correlated. In response to this paper Dulloo has reconsidered the issue and as discussed below is convinced of the first part of the hypothesis, that a P-ratio is fixed for an individual, but disagrees with the second part of an intra-individual constancy of the P-ratio during feeding and fasting. His 
argument is mainly based on consideration of the effects of growth on the P-ratio of energy gain.

The issue is in fact a complicated one. It could be that Dulloo's concern about the influence of growth or repletion of substantial amounts of body tissue is less relevant to the situation of variable short-term gains and losses of body weight which more closely resemble real life and which in the Payne-Dugdale model involve the random daily variation. Clearly the fact that during catch-up growth, fat repletion does occur at a faster rate than lean tissue repletion does imply a changing P-ratio and composition of repleted tissue over time (Ashworth, 1969; Ashworth \& Millward, 1986). What is important for long-term outcome however is the final P-ratio achieved and, notwithstanding Keys' description of 'post-starvation obesity' (Keys et al. 1950), there are few experimental data on long-term outcome.

In fact, on the basis of studies of the P-ratio during shortterm gains and losses of body energy challenges have been levelled at the proposition of a variable P-ratio as a determinant of fatness. Clugston \& Garlick (1982) reported leucine tracer balance data of diurnal (fasting-feeding) changes in protein balance in both lean and obese individuals, reporting no difference in the P-ratio between the lean and obese subjects. Whilst such studies have been criticized by Henry et al. (1989) on technical grounds, carefully controlled animal studies of lean and obese Zucker rats also showed that the initial response to fasting involved a similar P-ratio (Wijesinghe et al. 1991). In fact, the P-ratio was shown to fall progressively with time in the obese rats in contrast to a stable P-ratio in lean animals. These particular data are important in the context of another argument, which has developed in relation to the constancy of the P-ratio in the context of the control of $\mathrm{N}$ balance and adaptive changes in protein and amino acid metabolism which mediate adapative protein conservation.

First, the idea of protein-sparing during fasting when ketones replace glucose as a fuel for the brain, which derived from Cahill's work in the 1960s (Cahill, 1970), implies that there are adaptive reductions in protein mobilization during fasting, i.e. a fall in the P-ratio over time. Henry et al. (1988) argued that the experimental basis for the concept of adaptive protein conservation was inadequate and an artefact reflecting a failure to measure P-ratio rather than just nitrogen excretion. Parallel falls in both nitrogen excretion and energy mobilized can mean that the amount of nitrogen loss may fall while the P-ratio is constant. Henry et al. (1988) argued that the low nitrogen loss reported by Cahill (1970) for obese subjects is not observed in lean subjects and reflects a low intrinsic P-ratio in the obese rather than an adaptive decline during fasting which spares body protein (Henry et al. 1988). Elia \& Parkinson (1989) also reviewed the literature on fasting human studies and concluded that obese subjects did have lower P-ratios than lean subjects but were not able to deal with the question of a progressive change with time. In fact, the studies with fasting obese Zucker rats (Wijesinghe, 1991; Wijesinghe et al. 1991) did show that the protein sparing with fasting is a time-dependent adaptive function in obese Zucker rats (P-ratio falling from 0.159 (SD 0.025), day 1 to 0.084 (SD 0.011), day 5) but not in leaner Zucker rats (P-ratio 0.184 (SD 0.026), day 1 and 0.159 (SD 0.025), day 5). Differences in plasma ketones and thyroid hormone levels with fasting were shown to account for the different metabolic responses of the two rat phenotypes and it was assumed from these studies that the adaptive reduction in the P-ratio is a metabolic response to the magnitude of body fat stores. This idea is supported by other remarkable studies. During a 4-month winter fast before breeding, adult male emperor penguins lose about $20 \mathrm{~kg}$ before spontaneous refeeding. This weight loss involves initially a low Pratio of about 0.04 which is maintained until body fat is quite low after which a dramatic increase in the P-ratio occurs with the proportion of energy derived from protein increasing 14-fold (Robin et al. 1988). Furthermore, during a short 2-3 week spring fast when body fat stores are low, the P-ratio is 2.5 times higher than the initial low P-ratio observed during the winter fast. Taken together these data tend to indicate that the main difference in the P-ratio between individuals is the extent to which an adaptive reduction occurs, which in turn is a response to the extent of body fat stores. This is the opposite of the P-ratio being the determinant of fatness.

Second, there is considerable evidence to show that the P-ratio is a function of the dietary intake in terms of both energy and protein level. Coyer et al. (1987) showed that the P-ratio for energy gain increased dramatically to very high levels as energy intakes fell in growing rats. Indeed, as discussed by Coyer et al. (1987), in growing animals positive nitrogen balance can occur with an overall negative energy balance and this probably reflects the continuing anabolic drive on bone and related muscle growth with a high protein diet even with restricted energy (see Millward, 1995). However, it is not known whether a similar response would be observed in the adult. More recent work in the adult on the regulation of nitrogen balance does indicate that the P-ratio for both gain and loss is a function of the habitual protein intake. Price $e t$ al. (1994) showed that subjects habituated to increasing protein intakes exhibited gains and losses of protein during diurnal feeding and fasting which increased with habitual intakes. P-ratios calculated from the nitrogen balances and energy intakes assuming daily energy balance imply an increase in the P-ratios for gain from 0.01 on submaintenance intakes to 0.24 on very high protein intakes, with corresponding values of P-ratios for losses of 0.06 increasing to $0 \cdot 18$. Furthermore, this high P-ratio of fasting loss with a high protein intake adapts only slowly to a change to a lower protein intake (Quevedo et al. 1994). These responses appear to reflect an influence of dietary protein on an adaptive component of amino acid oxidation rates, occurring throughout the day and becoming in effect part of the metabolic demand for dietary protein (see Millward, 1997). The implication of this within the PayneDugdale model of course is that subjects adapted to a low protein intake with a low P-ratio should become fatter due to the lower thermogenic cost of energy deposition. We know of no evidence that this occurs in adult humans.

In summary, there is considerable doubt as to whether the assumptions about the P-ratio describing the control of the composition of tissue gained and lost central to the Payne-Dugdale model as written are entirely valid. This 
does not of course detract from its importance in highlighting the stabilizing effects of feedback from change in metabolic rate with change in body weight on changes in intake. The challenge for its supporters is to revise the model to include the variation in P-ratios over time which clearly occur.

\section{References}

Ashworth A (1969) Growth rates in children recovering from protein-calorie malnutrition. British Joumal of Nutrition 23, 835-845.

Ashworth A, Millward DJ (1986) Catch-up growth in children. Nutrition Reviews 44, 157-163.

Cahill GF Jr (1970) Starvation in man. New England Journal of Medicine 282, 668-672.

Clugston GA and Garlick PJ (1982) The response of protein and energy metabolism to food intake in lean and obese man. Human Nutrition: Clinical Nutrition 36C, 57-70.

Coyer PA, Rivers JPW \& Millward DJ (1987) The effect of dietary protein and energy restriction on heat production and growth costs in the young rat. British Journal of Nutrition 58, 73-85.

de Castro JM (1997) How can energy balance be achieved in freeliving human subjects? Proceedings of the Nutrition Society 56, $1-14$.

Dulloo AG (1997) Human pattern of hyperphagia and fuel partitioning during weight recovery after starvation: a theory of autoregulation of body composition. Proceedings of the Nutrition Society 56, 25-40.

Dulloo AG (1998) Partitioning between protein and fat during starvation and refeeding: is the assumption of intra-individual constancy of P-ratio valid? (Letter). British Journal of Nutrition, 79, 107-109.

Elia M \& Parkinson S (1989) Protein economy during human starvation (letter to the editor). European Journal of Clinical Nutrition 43, 139.

Garrow JS (1978) Energy balance and obesity in man. Amsterdam: North Holland Publishing Co.

Henry CJK, Payne PR \& Ghusain-Choueiri A (1997) Relationship between tissue mobilization and storage in the rat. British Journal of Nutrition 78, 131-141.

Henry CJK, Rivers JPW \& Payne PR (1988) Protein and energy metabolism in starvation reconsidered. European Journal of Clinical Nutrition 42, 543-549.
Henry CJK, Rivers JPW \& Payne PR (1989) Protein economy during human starvation (letter). European Journal of Clinical Nutrition 43, 142.

Keys A, Brozek J, Henchel A, Michelsen O \& Taylor HL (1950) The Biology of Human Starvation. Minnesota: University of Minnesota Press.

Millward DJ (1998) A protein-stat mechanism for the regulation of growth and maintenance of the lean-body mass. Nutrition Research Reviews 8, 93-120

Millward DJ (1997) Metabolic demands for amino acids and the human dietary requirement: Millward and Rivers (1988) revisited. Journal of Nutrition (In the Press).

Payne PR \& Dugdale AE (1977) A model for the prediction of energy balance and body weight. Annals of Human Biology 4, 525-535.

Price GM, Halliday D, Pacy PJ, Quevedo MR \& Millward DJ (1994) Nitrogen homeostasis in man: 1. Influence of protein intake on the amplitude of diurnal cycling of body nitrogen. Clinical Science 86, 91-102.

Quevedo MR, Price GM, Halliday D, Pacy PJ \& Millward DJ (1994) Nitrogen homeostasis in man: 3. Diurnal changes in nitrogen excretion, leucine oxidation and whole body leucine kinetics during a reduction from a high to a moderate protein intake. Clinical Science 86, 185-193.

Robin JP, Frain M, Sardet C, Groscolas R \& Maho YL (1988) Protein and lipid utilization during long-term fasting in emperor penguins. American Journal of Physiology 254, R61.

Wijesinghe DGNG (1991) Regulation of body composition and energy balance during undernutrition in the rat. $\mathrm{PhD}$ Thesis, University of London.

Wijesinghe DGNG, Millward DJ \& Rivers JPW (1991) Protein conservation in the obese Zucker rat during fasting. Proceedings of the Nutrition Society 50, 48A.

D. Joe Millward and D. G. N. G. Wijesinghe Centre for Nutrition and Food Safety School of Biological Sciences University of Surrey Guildford, Surrey $G U 25 X H$

United Kingdom 